\title{
Geotechnical properties of lateritic soil stabilized with sugarcane straw ash
}

\author{
*Amu, O.O., Ogunniyi, S.A. and Oladeji, O.O. \\ Department of Civil Engineering, Obafemi Awolowo University, Ile-Ife, Osun State, Nigeria \\ ${ }^{*}$ Corresponding author
}

\begin{abstract}
This research determined the geotechnical properties of lateritic soil modified with sugarcane straw ash with a view to obtaining a cheaper and effective replacement for the conventional soil stabilizers. Preliminary tests were performed on three samples, A, B and C for identification and classification purposes followed by the consistency limit tests. Geotechnical strength tests (compaction, California bearing ratio (CBR), unconfined compression test and triaxial) were also performed on the samples, both at the stabilized and unstabilized states (adding 2, 4, 6, and 8\% sugarcane straw ash). The results showed that sugarcane straw ash improved the geotechnical properties of the soil samples. Optimum moisture content increased from 19.0 to $20.5 \%, 13.3$ to $15.7 \%$ and 11.7 to $17.0 \%$, CBR increased from 6.31 to $23.3 \%, 6.24$ to $14.88 \%$ and 6.24 to $24.88 \%$ and unconfined compression strength increased from 79.64 to $284.66 \mathrm{kN} / \mathrm{m}^{2}, 204.86$ to $350.10 \mathrm{kN} / \mathrm{m}^{2}$ and 240.4 to $564.6 \mathrm{kN} / \mathrm{m}^{2}$ in samples A, B and C respectively. Sugarcane straw ash was therefore found as an effective stabilizer for lateritic soils.
\end{abstract}

Keywords: geotechnical property, sugarcane straw ash, stabilization, lateritic soil

\section{INTRODUCTION}

The needs for adequate provisions of transportation facilities are enormously increasing with increase in population and also the maintenance of the existing one. Highway engineers are faced with the problems of providing very suitable materials for the Highway construction. Owning to this fact, continuous researches have been carried and still being carried out by individual, firms and institutions on ways to improve the engineering properties of soils. The most available soils do not have adequate engineering properties to really bear the expected wheel load. So improvisations have to be made to make these soils better. These lead to the concept called soil stabilization which is any treatment (including, technically, compaction) applied to a soil to improve its strength and reduce is vulnerability to water, if the treated soil is able to withstand the stresses imposed on it by traffic under all weather conditions without excessive deformation, then it is generally regarded as stable.

Several highways pavement in Nigeria roads are failing due to lack of use of soil with adequate engineering strength. So the need for improvement of the engineering properties of soil has been a paramount concern to the transportation engineers. The ability to blend the naturally abundant lateritic soil with some chemical reagent to give it better engineering properties in both strength and waterproofing has been of paramount importance to the transportation engineers. In bid to improve the engineering properties of soil to make it suitable for road construction, several researches on soils stabilization have been carried out. Sugarcane straw is a major by product in the manufacturing of sugar in the sugar industries. Proper disposal of waste product has been a global concern. In order to make sugarcane straw a useful material, several researches have been conducted. Some of the researches show that sugarcane straw ash contains a high amount of silicon oxide making it highly pozzolanic. The aim of this study is to determine the effect of sugarcane straw ash stabilization on the geotechnical properties of lateritic soil.

\section{Lateritic Soil and Stabilization:}

The word Laterite describes no material with reasonable constant properties. To those in the temperate countries, it could be described as a red friable clay surface. To those in the hilly tropical countries, it could be described as a very hard homogenous vescular massive clinker - like materials with a framework of red hydrated ferric oxides of vescular infill of soft aluminium oxides of yellowish colour and in less hilly country, it could exist as a very hard, or soft coarse angular red. Lateritic soils as a group rather than well-defined materials are most commonly found in a leached soils of humid tropics. Laterite is a surface formation in hot and wet 
tropical areas which is enriched in iron and aluminium and develops by intensive and long lasting weathering of the underlying parent rock (Wikipedia, 2007).

In order to fully appreciate the usefulness of lateritic soil, its problems (in both field and laboratory) would have to be identified and useful solutions applied. The mechanical instability, which may manifest in form of remoulding and manipulation, results in the breakdown of cementation and structure. The engineering properties affected by this mechanical instability include particle size, Atterberg's limits, and moisture-density distribution. Thermal instability is shown through sensitivity to drying to be described as potential self-stabilization. The affected engineering parameters are Atterberg's limits, particle size distribution. The effects of these problems therefore affect the strength of the material. Soil stabilization is any treatment applied to a soil to improve its strength and reduce is vulnerability to water, if the treated soil is able to withstand the stresses imposed on it by traffic under all weather conditions without deformation, then it is generally regarded as stable. This definition applies irrespective of whether the treatment is applied to a soil in situ or after the soil has been removed and placed in a pavement or embankment (O'Flaherty, 2002). Soil stabilization methods can be divided into two categories, namely mechanical and chemical. Mechanical stabilization is the blending of different grades of soils to obtain a required grade. Chemical stabilization is the blending of the natural soil with chemical agents. Several blending agents have been used to obtain different effects. The most commonly used agents are Portland cement; asphalt binders and lime.

Geotechnical Properties of Soils: The designs of earth structures require knowledge on the behaviour and stress-related deformability of soils that will support the structure and the geological conditions of the soil under consideration. The geotechnical properties of a soil such as grain size distribution, plasticity, compressibility, shear strength, permeability, soil compaction, California bearing ratio, shear strength and so on, are used in predicting the behaviour of soil when subject to loads. These properties can be assessed by proper laboratory or in situ tests. In situ determination of these properties avoids the sample disturbances that occur during field exploration. However, under certain circumstances, all of the needed parameters cannot be determined or are not determined because of economic or other reasons.
Pozzolan and Sugarcane Straw Ash: Pozzolan can be defined as a siliceous, or siliceous and aluminous material, which in itself possesses little or no cementations value but will, in a finely divided form, such as a powder or liquid and in the presence of moisture, chemically reach with calcium hydroxide at ordinary temperatures to form permanent, insoluble compounds possessing cementious properties (Moxie-intl., 2006). A pozzolan is broadly defined as an amorphous or glassy silicon or aluminosilicate material that reacts which calcium hydroxide formed during the hydration of Portland cement in concrete to create additional cementitous material in the form of calcium silicate and calcium silicoaluminate hydrates. There are majorly two types of pozzolan namely, the natural pozzolan and the artificial pozzolan. Natural pozzolans are present on earth's surface such as diatomaceous earth, volcanic ash, opaline shale, pumicite, and tuff. Natural pozzolans have been used in dam controls and alkali-silica reaction. Artificial pozzolans include coal fly ash (pulverized fuel ash or PFA), ground granulated blast furnace slag, silica fume, and metakaolin (calcined clay). The common feature of all these pozzolans is that they are silicates or aluminosilicates that have been converted to amorphous or glass phases in a high temperature furnace or combustion chamber, followed by rapid cooling or quenching under various conditions.

Sugarcane (Saccharum) is a genus of 6 to 37 species (depending on taxonomic interpretation) of tall perennial grasses (family Poaceae, tribe Andropogoneae), native to warm temperate to tropical regions of the Old World. They have stout, jointed, fibrous stalks that are rich in sugar and measure 2 to 6 meters tall. All of the sugarcane species interbreed, and the major commercial cultivars are complex hybrids (Wikipedia, 2007b). Sugarcane was originally from tropical South Asia and Southeast Asia. Different species likely originated in different locations with $S$. barberi originating in India and S. edule and S. officinarum coming from New Guinea. The thick stalk stores energy as sucrose in the sap. From this juice, sugar is extracted by evaporating the water. Crystallized sugar was reported 5000 years ago in India. Plate 1 shows cut sugarcane. 


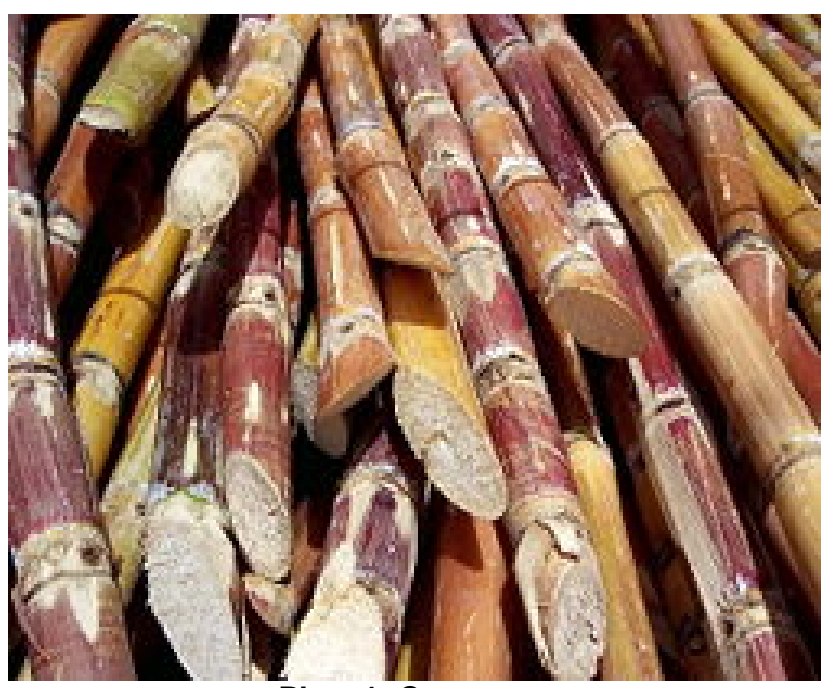

Plate 1: Cut sugarcane

Several experiments and papers discuss the characterization of sugar industry solid waste as pozzolanic materials (Fri'as M. and Cement and Concrete Research, 2005). Table 1 shows the chemical composition of sugarcane straw ash. It was already known that sugarcane bagasse and sugarcane straw (sugarcane leaves) can be recycled in the manufacture of commercial cements and other Table 1: Chemical composition for sugarcane straw ashes composites, either as raw material or as pozzolanic material. For use as pozzolans, the agricultural wastes need prior calcination but pozzolanic activation can vary substantially as a result of the calcining conditions and the source of the materials. However, there are contradictory reports about the pozzolanic effectiveness of sugarcane bagasse ash, possibly due to the use of different calcining temperatures (Paya' et al. 2002). It has been reported that sugarcane straw ash obtained from heaps of open-air burnt straw in the vicinity of a sugar factory showed a high pozzolanic activity (Martirena et al. 1998). In recent years, the possibility of mixing this solid waste of sugarcane with clay has been evaluated by getting an agglutinative material which permits an easy handling as well as an improvement in the environmental aspects (Middendorf et al. 2003) The research of Villar-Cocin $\sim$ a et al. (2003) studied the pozzolanic behaviour of a mixture of sugarcane straw with 20 and $30 \%$ clay burned at 800 and $1000^{\circ} \mathrm{C}$ and calcium hydroxide and proposed a kinetic-diffusive model for describing the pozzolanic reaction kinetics.

\begin{tabular}{|l|l|l|}
\hline Oxides & $\mathbf{8 0 0} \mathbf{C}$ & $\mathbf{1 0 0 0 ^ { \circ } \mathbf { C }}$ \\
\hline $\mathrm{SiO}_{2}$ & 70.20 & 70.99 \\
\hline $\mathrm{Al}_{2} \mathrm{O}_{3}$ & 1.93 & 2.08 \\
\hline $\mathrm{Fe}_{2} \mathrm{O}_{3}$ & 2.09 & 2.25 \\
\hline $\mathrm{CaO}$ & 12.20 & 12.44 \\
\hline $\mathrm{MgO}$ & 1.95 & 2.01 \\
\hline $\mathrm{K} 2 \mathrm{O}$ & 3.05 & 3.10 \\
\hline $\mathrm{Na}_{2} \mathrm{O}$ & 0.50 & 0.56 \\
\hline $\mathrm{TiO}_{2}$ & 0.02 & 0.02 \\
\hline $\mathrm{P}_{2} \mathrm{O}_{5}$ & 1.40 & 1.37 \\
\hline $\mathrm{SO}_{3}$ & 4.10 & 4.35 \\
\hline $\mathrm{Ll}_{2} \mathrm{O}$ & 1.81 & 0.52 \\
\hline
\end{tabular}

(Source Fri'as and Concrete Research, 2005)

\section{MATERIALS AND METHODS}

Materials: The materials used for this study were: lateritic soil, water and sugarcane straw ash (SCSA). Three lateritic soil samples A, B and C were collected from different locations at lle-Ife, Osun State, Nigeria. They were all collected at depths representative of the soil stratum and not less than the $1.2 \mathrm{~m}$ below the natural ground level. These were kept safe and dry in jute bags in the Geotechnics laboratory of the
Department of Civil Engineering, Obafemi Awolowo University, lle-lfe and marked, indicating the soil description, sampling depth and date of sampling. They were air dried for two weeks to allow partial elimination of natural water which may affect analysis, then sieved with sieve No. $4(4.76 \mathrm{~mm}$ opening) to obtain the final soil samples for the tests. After the drying period, lumps in the samples were slightly pulverized with minimal pressure. 
Am. J. Sci. Ind. Res., 2011, 2(2): 323-331

Sugarcane straws were obtained from a sugarcane depot at Sabo, Ile Ife, Osun State, Nigeria (Plate 2). The straws were spread out on the ground and air dried to facilitate easy burning. After air drying, the sugarcane straws were burnt openly into ash (Plate 3 ) and collected in polythene bags, stored under room temperature until used. The SCSA was sieved through BS sieve $75 \mu \mathrm{m}$ to get the very fine ash (Plate 4). It was ensured that the sugarcane straw ash remained covered before and after use to prevent moisture and contaminations from other materials. Pipe borne water from Opa Dam, Obafemi Awolowo University, Ile-Ife, Osun State, Nigeria was used.

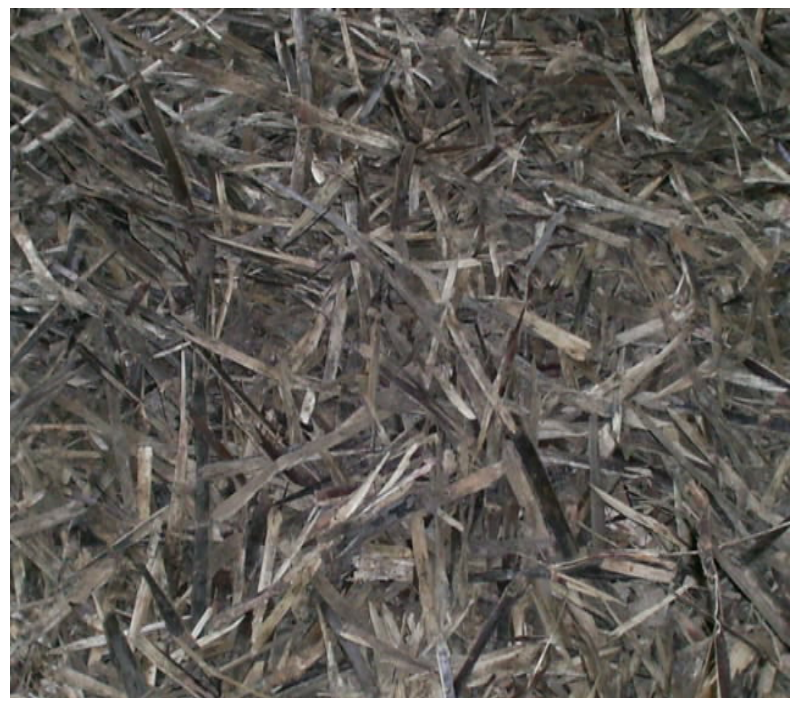

Plate 2: Sugarcane straw

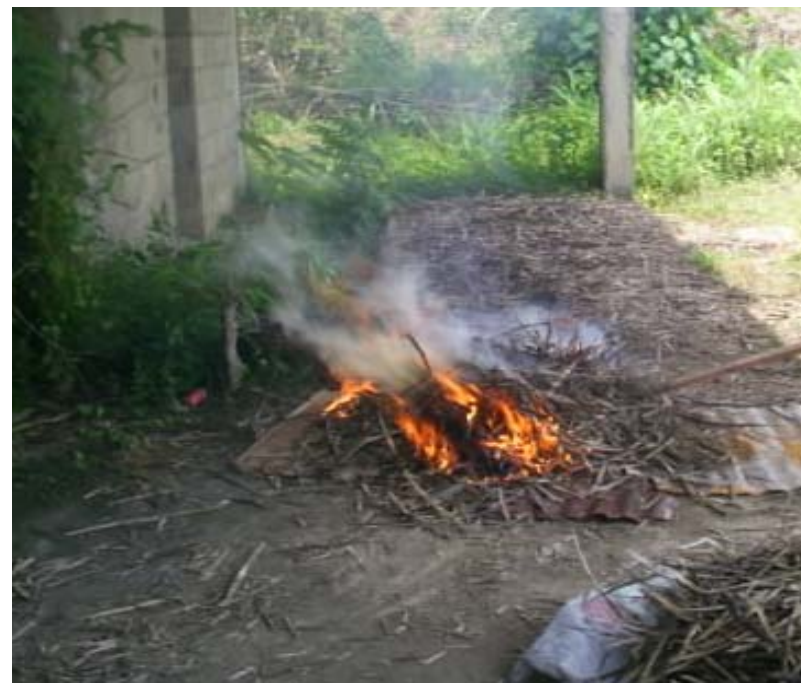

Plate 3: Burning sugarcane straw

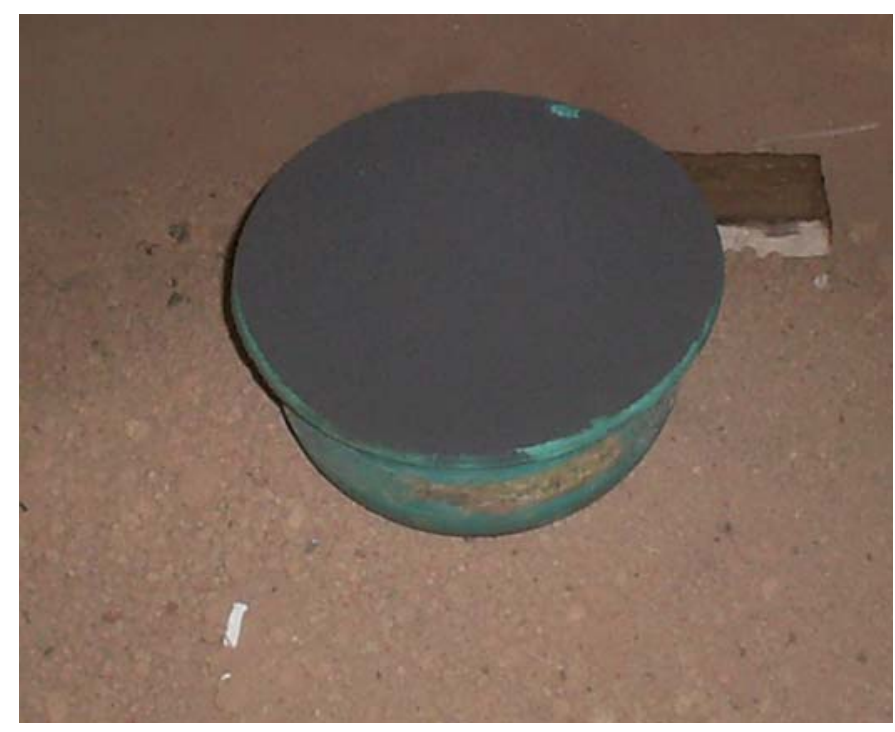

Plate 4: Sugarcane straw ash (SCSA)

Methods: Classification test (natural moisture content, specific gravity, particle size analysis and Atterberg's limits) and engineering property test (compaction, California bearing ratio (CBR), unconfined compression test and unconsolidated undrained triaxial) were performed on the unstabilized samples A, B and C. Sugarcane straw ash was then added to each of the samples in 2, 4, 6 and $8 \%$ by weight of samples. Atterberg's limit and the engineering property tests were repeated on the SCSA stabilized samples. The optimum moisture content (OMC) obtained from the compaction test of each varied percentage of sugarcane straw ash (SCSA) was used for the engineering property tests (CBR, unconfined compression and unconsolidated undrained triaxial) to determine the effect of sugarcane straw ash on the geotechnical properties of the samples.

\section{RESULTS AND DISCUSSION}

The results from the preliminary tests (grain size analysis, natural moisture contents, specific gravity, and Atterberg's limits) as well as the engineering property tests (compaction, California Bearing Ratio (CBR), unconfined compression test and unconsolidated undrained triaxial) are discussed below.

Classification Test: Table 2 shows the summary results of the preliminary analysis of soil samples. The natural moisture content of samples A, B and C were $10.71,14.91$ and $14.69 \%$ respectively. Sample 
A had the lowest natural moisture content while sample B had the highest. This is a function of the void ratios and the specific gravities of the samples. This showed that the soil samples contained appreciable amount of moisture which is largely affected by the climatic condition. The specific gravities of sample A, B and C are 2.42, 2.58 and 2.68 respectively. This values fall within that given in Das, (2000) for clay minerals, as halloysite (2.0-2.55) and sodium and calcium feldspar (2.62-2.76). The Table 2: Summary of the preliminary analysis of soil samples

\begin{tabular}{|l|l|l|l|l|l|l|l|}
\hline Sample & $\begin{array}{l}\text { Natural } \\
\text { Moisture } \\
\text { Content (\%) }\end{array}$ & $\begin{array}{l}\text { Specific } \\
\text { Gravity }\end{array}$ & $\begin{array}{l}\text { Liquid } \\
\text { Limit (\%) }\end{array}$ & $\begin{array}{l}\text { Plastic } \\
\text { Limit (\%) }\end{array}$ & $\begin{array}{l}\text { Plastic } \\
\text { Index (\%) }\end{array}$ & $\begin{array}{l}\text { AASTHO } \\
\text { classification }\end{array}$ & Soil Type \\
\hline A & 10.71 & 2.42 & 41.60 & 30.95 & 10.60 & A-2-7(0) & Silty \\
\hline B & 14.91 & 2.58 & 43.30 & 25.41 & 17.89 & A-2-7(0) & Silty \\
\hline C & 14.69 & 2.68 & 59.40 & 38.74 & 20.66 & A-2-7(0) & Silty \\
\hline
\end{tabular}

The results of the Atterberg's limits test (Liquid Limits (LL), Plastic Limits (PL) and Plastic Index (PI)) on the samples are shown in Table 3. The LL, PL and PI of the natural soil samples are $41.60,30.95$ and $10.60 \%$ respectively for sample $A ; 43.30,25.41$ and $17.89 \%$ respectively for sample $B$ and $59.40,38.74$ and $20.66 \%$ respectively for sample $C$.

According to Whitlow (1995), liquid limit less than $35 \%$ indicates low plasticity, between $35 \%$ and $50 \%$ indicates intermediate plasticity, between $50 \%$ and $70 \%$ high plasticity and between $70 \%$ and $90 \%$ very high plasticity and greater than $90 \%$ extremely high plasticity. This shows that samples $A$, and $B$, have low plasticity while sample $C$ has high plasticity. The addition of sugarcane straw ash in 2, 4, 6 and $8 \%$ to the samples caused changes in the liquid limits and plastic limits of all the samples, which are shown in Table 3. The plasticity indices of samples B and C decreased from 17.89 to 10.36 and 20.66 to 15.54 respectively. These reductions in plasticity indices are indicators of soil improvement.

Engineering Test: The summary of the results are shown in Table 4. The unstabilized Optimum Moisture Contents (OMC) for the samples are 19.0, 13.3 and $11.7 \%$ with Maximum Dry Densities (MDD) of 2020,2010 and $1860 \mathrm{~kg} / \mathrm{m}^{3}$ respectively for samples $A, B$ and $C$. The addition sugarcane straw ash in 2, 4, 6 and $8 \%$ by weight of sample generally increased OMC and decreased MDD in all samples. The OMC increased from 19.0 to $20.5 \%, 13.3$ to $15.7 \%$ and 11.7 to $17.0 \%$ respectively in samples $A$, samples were classified using the AASHTO soil classification system. All the samples fell within the granular materials under the general classification as their percentages passing $75 \mu \mathrm{m}$ sieve were all less than $35 \%$. They all fell within A-2 groups. Based on their Liquid Limit (LL) and Plastic Index (PI), samples $A, B$ and $C$ were further classified as $A-2-7(0), A-2-$ $7(0)$ and $A-2-7(0)$ respectively.

\section{$\mathrm{B}$ and C. The MDD decreased from 2020 to} $1890 \mathrm{~kg} / \mathrm{m}^{3}, 2010$ to $1880 \mathrm{~kg} / \mathrm{m}^{3}$ respectively in samples $A$ and $B$ and increased from $1860 \mathrm{~kg} / \mathrm{m}^{3}$ to $1790 \mathrm{~kg} / \mathrm{m}^{3}$ in samples $C$. The increase in OMC is probably due to the additional water held within the flocculent soil structure due to excess water absorbed as a result of the porous property of sugarcane straw ash. An increase in MDD is a general indication of soil improvement; however the addition of sugarcane straw ash reduced the MDDs. The opinion of Das, (2000) revealed that a changedown in dry density might occur due to both the particle size and specific gravity of the soil and stabilizer

The result of the California Bearing Ratio (CBR) test is summarized in Figs. 1-3. The CBR of all samples increased considerably with sugarcane straw ash stabilization. The optimum CBR values in sugarcane straw ash were almost $400 \%$ higher than the unstabilized samples A and C and $220 \%$ for sample $B$. This shows that the load bearing capacity of the samples increased considerably with the sugarcane straw ash.

Table 5 shows the summary of the unconfined compression test results. It is a special type of unconsolidated-undrained test that is commonly used for clay specimens where the confining pressure $\left(\sigma_{3}\right)$ is 0 and the major principal stress $\left(\sigma_{1}\right)$ is the unconfined compression strength $\left(q_{u}\right)$. The unconfined compression strength of samples $A$, and $B$ increased considerably with the addition of 
sugarcane straw ash. The sample strengths rose from 79.64 to $284.66 \mathrm{kN} / \mathrm{m}^{2}, 204.86$ to $350.10 \mathrm{kN} / \mathrm{m}^{2}$ and 240.4 to $564.6 \mathrm{kN} / \mathrm{m}^{2}$ in samples $\mathrm{A}, \mathrm{B}$ and $\mathrm{C}$ respectively. According to Das, (2000), unconfined compression strength is the fundamental determinant of consistency of a clayey soil; between $0-25 \mathrm{kN} / \mathrm{m}^{2}$ indicates very soft, between $25-50 \mathrm{kN} / \mathrm{m}^{2}$ indicates soft, between $50-100 \mathrm{kN} / \mathrm{m}^{2}$ indicates medium and between $100-200 \mathrm{kN} / \mathrm{m}^{2}$ indicates stiff, $200-400 \mathrm{kN} / \mathrm{m}^{2}$ indicates very stiff and greater than $400 \mathrm{kN} / \mathrm{m}^{2}$ indicates hard clay. Soil sample A changed from the initial medium consistency to very stiff at $6 \%$ stabilization. Although the unconfined compression strength of Sample B increased from 204.86 to $350.10 \mathrm{kN} / \mathrm{m}^{2}$, its consistency remained as very stiff.

The triaxial test is the most common and versatile test used to determine the stress-strain properties and shear strength parameters of soil. In Figure 4 the shear strength of the samples increased considerably with the addition of sugarcane straw ash.

Table 3: Summary of Atterberg's limits test

\begin{tabular}{|c|c|c|c|c|}
\hline Sample & Percentage Stabilization & Liquid Limit (LL)\% & Plastic Limit (PL)\% & Plastic Index (PI)\% \\
\hline \multirow{5}{*}{ A } & $0 \%$ sugarcane straw ash & 41.6 & 30.95 & 10.60 \\
\hline & $2 \%$ sugarcane straw ash & 38.65 & 26.88 & 10.65 \\
\hline & $4 \%$ sugarcane straw ash & 45.50 & 29.32 & 16.18 \\
\hline & $6 \%$ sugarcane straw ash & 28.50 & 15.57 & 12.93 \\
\hline & $8 \%$ sugarcane straw ash & 25.00 & 13.94 & 4.43 \\
\hline \multirow{5}{*}{$B$} & $0 \%$ sugarcane straw ash & 43.30 & 25.41 & 17.89 \\
\hline & $2 \%$ sugarcane straw ash & 38.35 & 25.47 & 12.88 \\
\hline & $4 \%$ sugarcane straw ash & 36.00 & 25.64 & 10.36 \\
\hline & $6 \%$ sugarcane straw ash & 39.85 & 27.24 & 12.61 \\
\hline & $8 \%$ sugarcane straw ash & 40.80 & 27.85 & 12.95 \\
\hline \multirow{5}{*}{ C } & $0 \%$ sugarcane straw ash & 59.40 & 38.74 & 20.66 \\
\hline & $2 \%$ sugarcane straw ash & 46.00 & 27.86 & 18.14 \\
\hline & $4 \%$ sugarcane straw ash & 44.80 & 29.26 & 15.54 \\
\hline & $6 \%$ sugarcane straw ash & 47.90 & 30.40 & 17.50 \\
\hline & $8 \%$ sugarcane straw ash & 49.20 & 30.00 & 19.20 \\
\hline
\end{tabular}

Table 4. Summary of compaction test results

\begin{tabular}{|c|c|c|c|c|}
\hline Sample & Percentage stabilization & $\begin{array}{l}\text { Optimum Moisture Content } \\
\text { (OMC) (\%) }\end{array}$ & $\begin{array}{l}\text { Maximum } \\
\text { Density }\left(\mathrm{kg} / \mathrm{m}^{3}\right)\end{array}$ & Dry \\
\hline \multirow{5}{*}{ A } & $0 \%$ SCSA & 19.0 & 2020 & \\
\hline & $2 \%$ SCSA & 19.7 & 1960 & \\
\hline & $4 \%$ SCSA & 17.5 & 1990 & \\
\hline & $6 \%$ SCSA & 17.5 & 1985 & \\
\hline & $8 \%$ SCSA & 20.5 & 1890 & \\
\hline \multirow{5}{*}{ B } & $0 \%$ SCSA & 13.3 & 2010 & \\
\hline & $2 \%$ SCSA & 14.5 & 1915 & \\
\hline & $4 \%$ SCSA & 14.3 & 1880 & \\
\hline & $6 \%$ SCSA & 15.7 & 1880 & \\
\hline & $8 \%$ SCSA & 15.0 & 1890 & \\
\hline \multirow{5}{*}{ C } & $0 \%$ SCSA & 11.7 & 1860 & \\
\hline & $2 \%$ SCSA & 16.3 & 1805 & \\
\hline & $4 \%$ SCSA & 16.0 & 1790 & \\
\hline & $6 \%$ SCSA & 16.7 & 1775 & \\
\hline & $8 \%$ SCSA & 17.0 & 1750 & \\
\hline
\end{tabular}


Am. J. Sci. Ind. Res., 2011, 2(2): 323-331

Table 5. Variation of unconfined compression strength with Stabilization mix

\begin{tabular}{|c|c|c|}
\hline Sample & Percentage stabilization & $\begin{array}{l}\text { Unconfined compression } \\
\text { strength }\left(q_{u}\right) \mathrm{kN} / \mathrm{m}^{2}\end{array}$ \\
\hline \multirow{5}{*}{$A$} & $0 \%$ SCSA & 79.64 \\
\hline & $2 \%$ SCSA & 179.18 \\
\hline & $4 \%$ SCSA & 209.98 \\
\hline & $6 \%$ SCSA & 284.66 \\
\hline & $8 \%$ SCSA & 179.18 \\
\hline \multirow{5}{*}{$\mathrm{B}$} & $0 \%$ SCSA & 204.86 \\
\hline & $2 \%$ SCSA & 165.44 \\
\hline & $4 \%$ SCSA & 227.04 \\
\hline & $6 \%$ SCSA & 350.10 \\
\hline & $8 \%$ SCSA & 325.01 \\
\hline \multirow{5}{*}{$\mathrm{C}$} & $0 \%$ SCSA & 240.4 \\
\hline & $2 \%$ SCSA & 355.1 \\
\hline & $4 \%$ SCSA & 472.3 \\
\hline & $6 \%$ SCSA & 564.6 \\
\hline & $8 \%$ SCSA & 521.0 \\
\hline
\end{tabular}

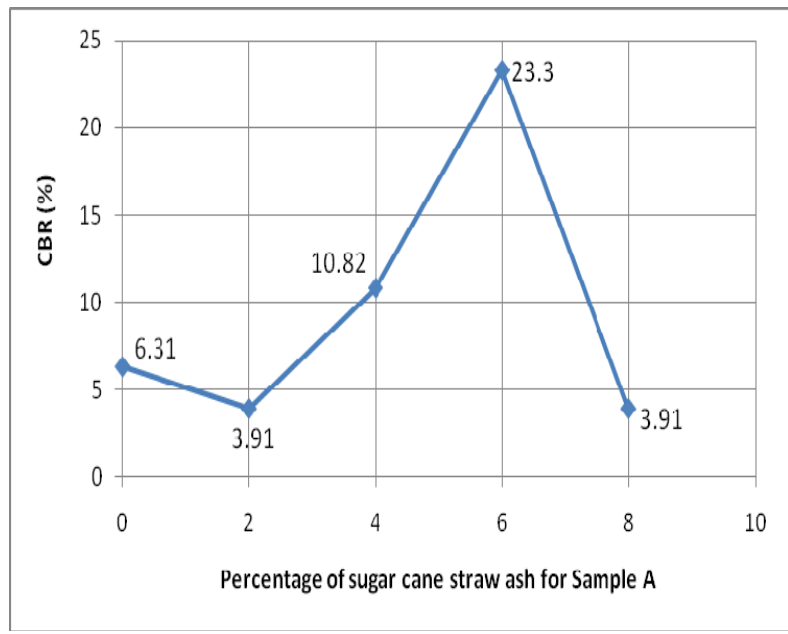

Fig. 1: Variation of CBR of sample A with application of sugarcane straw ash 
Am. J. Sci. Ind. Res., 2011, 2(2): 323-331

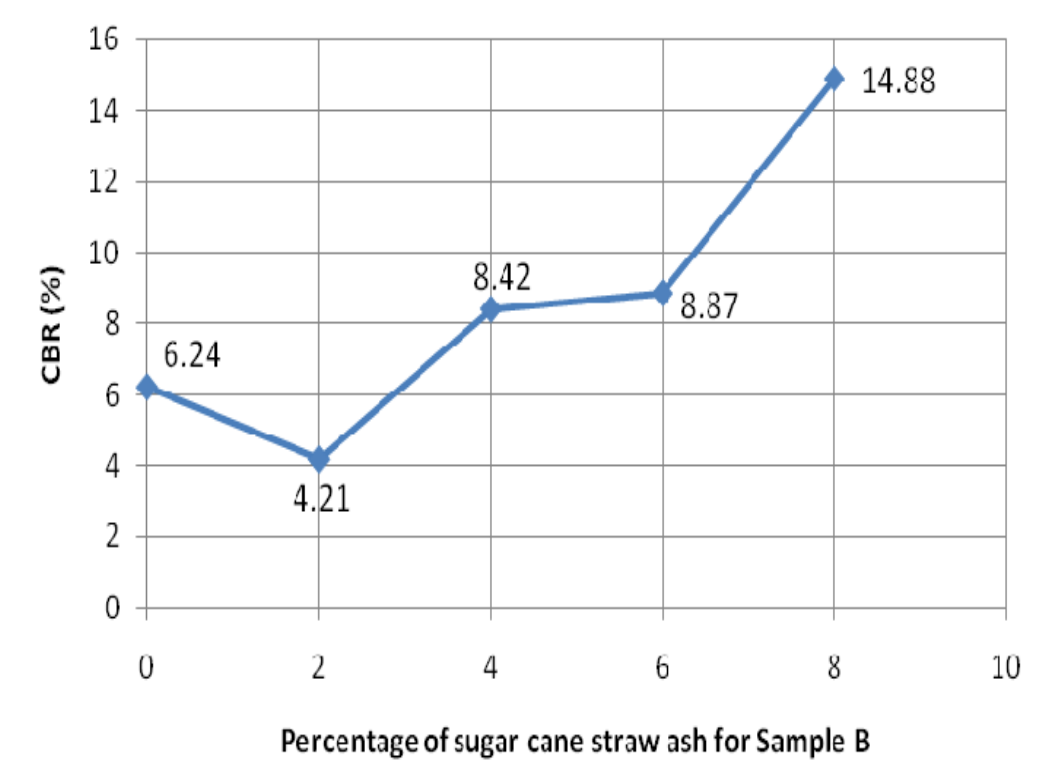

Fig 2: Variation of CBR of sample B with application of sugarcane straw ash

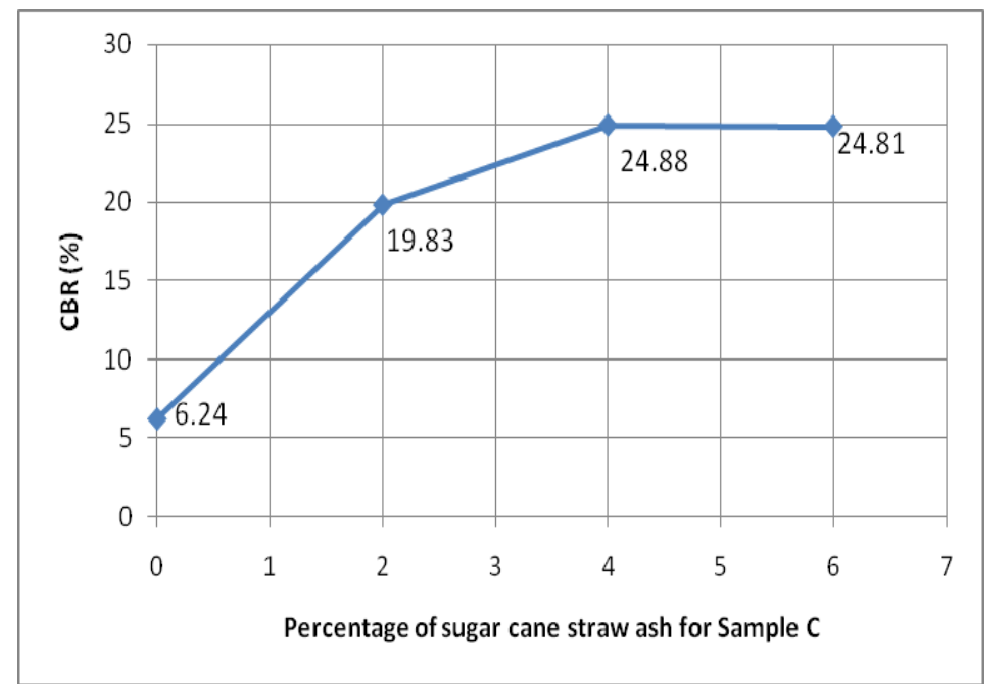

Fig 3: Variation of CBR of sample $C$ with application of sugarcane straw ash 
Am. J. Sci. Ind. Res., 2011, 2(2): 323-331

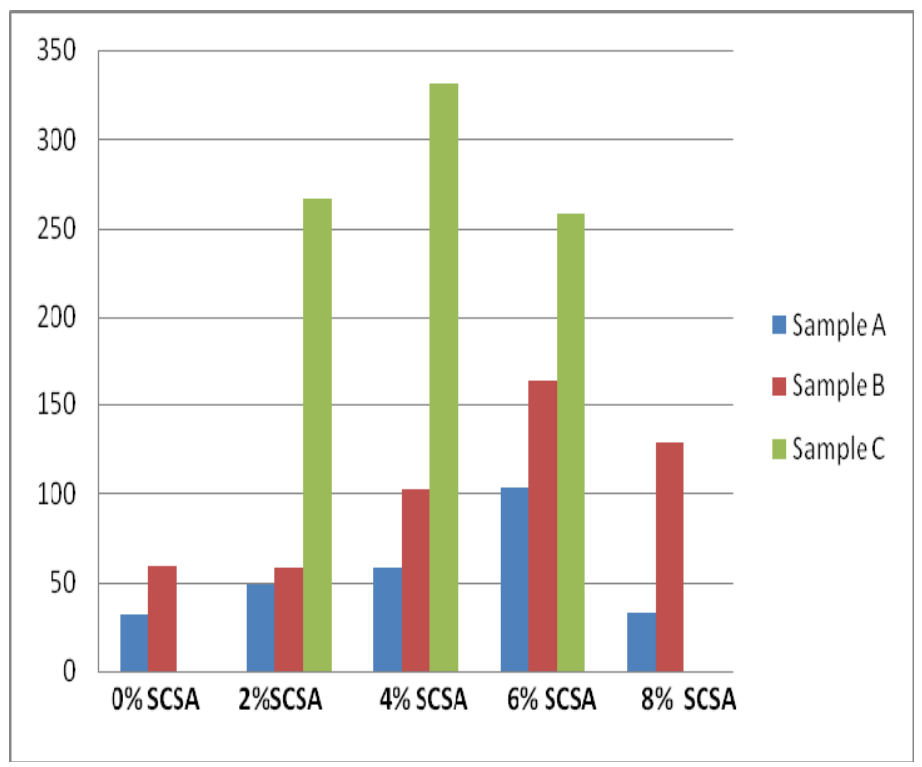

Fig 4. Variation of Shear strength of sample A, B and C with application of sugarcane straw ash

\section{CONCLUSION}

Based on the summary of results discussed above, it was concluded that sugarcane straw ash was an effective stabilizer for improving the geotechnical properties of lateritic soil samples.

\section{REFERENCES}

Das, B.M (2000). Fundamental of Geotechnical Engineering. $4^{\text {th }}$ ed. Thomson Learning, USA. Fri'as, M. and Cement and Concrete Research (2005). Sugar cane straw ash.

$<$ http://www.ietcc.csic.es/fileadmin/Ficheros_IETcc/Departa mentos/Sintesis/documentos/publicaciones/publicacio nes_2007/WM_27_2007__SCStraw.pdf>.

Martirena, J.F., Middendorf, B. and Budelman, H (1998). Use of wastes of the sugar industry as pozzolan in lime-pozzolan binders: Study of the reaction. Cement Concrete Research. 28: 1525-1536.

Middendorf, B., Mickley, J., Martirena, J.F. and Day, R.L (2003). Masonry wall materials prepared by using agriculture waste, lime and burnt clay. In: Masonry: Opportunities for the 21st Century. eds. Throop D. and R. Klingner. ASTM STP 1432, West Conshohocken, PA, pp. 274-283.
Moxie-intl (2006). Definition of pozzolan.

<http://www.moxieintl.com/glossary.htm> 31th March, 2008.

O'Flaherty, C.A (2002). Highways: The location, design and maintenance of road pavements. $4^{\text {th }}$ ed. Butterworth Heinemenn, Jordan Hill Oxford.

Paya,' J., Monzo,' J., Borrachero, M.V., Dı'az, P. and Ordon ez, L.M (2002). Sugarcane bagasse ash (SCBA): Studies on its properties for reusing in concrete production. Journal of Chemical Technology and Biotechnology. 77: 321-325.

Villar-Cocin a, E., Valencia-Morales, E., Gonza'lezRodri'guez, R. and Herna'ndez-Rui'z, J (2003). Kinetics of the pozzolanic reaction between lime and sugar cane straw ash by electrical conductivity measurement: A kinetic-diffusive model. Cement Concrete Research. 33:517-524.

Whitlow, R (1995). Basic Soil Mechanics. $3^{\text {rd }}$ ed. Addison Wesley Longman Limited, Edinburgh Gate.

Wikipedia (2007). About lateritic soil. <http://en.wikipedia.org/wiki/Laterite> 29th March, 2008.

Wikipedia (2007b). About Sugar cane. < http://en.wikipedia.org/wiki/Sugarcane> 22th May, 2008 